\title{
Intestinal microbiota and its relationship with necrotizing enterocolitis
}

\author{
Ravi Mangal Patel ${ }^{1,2}$ and Patricia W. Denning ${ }^{1,2}$
}

Necrotizing enterocolitis (NEC) is a leading cause of morbidity and mortality in infants born prematurely. After birth, the neonatal gut must acquire a healthy complement of commensal bacteria. Disruption or delay of this critical process, leading to deficient or abnormal microbial colonization of the gut, has been implicated as key risk factor in the pathogenesis of NEC. Conversely, a beneficial complement of commensal intestinal microbiota may protect the immature gut from inflammation and injury. Interventions aimed at providing or restoring a healthy complement of commensal bacteria, such as probiotic therapy, are currently the most promising treatment to prevent NEC. Shifting the balance of intestinal microbiota from a pathogenic to protective complement of bacteria can protect the gut from inflammation and subsequent injury that leads to NEC. Herein, we review the relationship of intestinal microbiota and NEC in preterm infants.

$\mathbf{N}$ ecrotizing enterocolitis (NEC) is a major cause of mortality and morbidity in infants born prematurely $(1,2)$. Approximately $7 \%$ of very-low-birth-weight $(\leq 1,500 \mathrm{~g}$ at birth) infants will develop NEC. More worrisome, 20-30\% of the very-low-birth-weight infants with NEC will die (3) and the remaining survivors will be at substantial risk for long-term complications, including impaired neurodevelopment and short bowel syndrome (4). Although the underlying pathogenesis of NEC is not completely understood, current evidence suggests a multifactorial pathophysiology that can be categorized into four areas: premature birth, abnormal intestinal microbiota, enteral feeding, and other potential factors (Figure 1).

\section{RISK FACTORS FOR NEC}

Premature birth is the major determinant of NEC, as this disease almost exclusively occurs in infants born prematurely and the incidence of NEC is inversely proportional to the gestational age at birth $(5,6)$. Several aspects of immature intestinal function in preterm infants may contribute to NEC predisposition, including the inflammatory propensity of the immature gut $(7,8)$, decreased intestinal barrier function $(9,10)$, and impaired intestinal immune defenses (11). Additional potential risk factors that are controversial and based on observational data but may confer an increased risk of NEC include impaired intestinal oxygen delivery from anemia (12), aberrant gut vascular regulation (13), and/or red blood cell transfusion (14), which may lead to gut reperfusion injury. Further, the use of formula instead of breastmilk increases the risk of NEC $(15,16)$. Although older studies suggested that rapid and aggressive advancement of enteral feedings were associated with an increased risk of NEC $(17,18)$, recent meta-analyses have not shown an effect of aggressive feeding or delayed initiation of enteral feeding on NEC $(19,20)$. Finally, abnormal intestinal microbiota, either from a lack of beneficial commensal microbes, a low diversity of bacteria or a preponderance of pathogenic bacteria, are likely to contribute to the risk of NEC. In this review article, we discuss the role of the intestinal microbiota in the pathogenesis of NEC.

\section{ROLE OF MICROBIOTA IN INTESTINAL HEALTH AND HOMEOSTASIS}

The human intestine is the largest immune organ in the body and a major interface to the external environment, where the gut must protect against harmful antigens, such as toxins and pathogens, while housing and tolerating beneficial commensal bacteria. This is a difficult task, as alterations in the balance between bacterial pathogens and commensal bacteria shift a gut from healthy intestinal homeostasis (21) to uncontrolled inflammation that can lead to injury and, potentially, the development of NEC (2). Commensal bacteria provide a number of benefits to the human host. These benefits include maintenance of intestinal homeostasis and protection from injury $(22,23)$, support of digestion $(24,25)$, and regulation of intestinal immune function $(26,27)$. After birth, the immature neonate must acquire and sustain these beneficial commensal microbes as they begin to enter the intestinal lumen from the environment. Eventually, the number of bacteria will outgrow the host by a factor of ten to one $(28,29)$.

Although the newborn infant's gut has previously been thought to be a sterile environment, emerging evidence suggests the potential that gut microbial acquisition may begin in utero under nonsterile intrauterine conditions. This is suggested by correlation of microbiota in meconium with those 


\section{Intestinal microbiota and NEC $\quad$ Review}

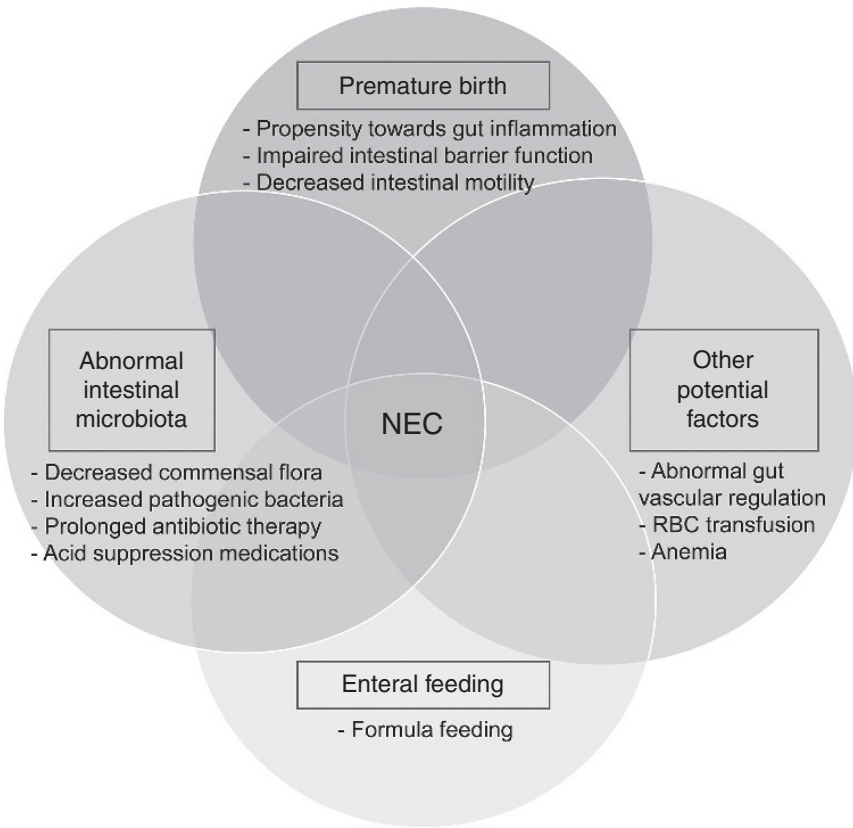

Figure 1. Risk factors for NEC. Figure depicts the multiple risk factors that influence the development of NEC in premature infants. Abbreviations: $\mathrm{NEC}$, necrotizing enterocolitis; $\mathrm{RBC}$, red blood cell.

found in amniotic fluid (30) as well as detection of acinetobacter in the airways of preterm infants at birth (31). However, until these findings are replicated, they should be viewed with some caution given the concerns for effects of bacterial contamination in nonculture-based sequencing methods (32) and sampling under conditions where the amnion may not be intact.

\section{MAJOR EVENTS IN THE DEVELOPMENT OF THE INTESTINAL MICROBIOME}

The fetal gut under physiologic conditions rapidly begins to acquire commensal microbiota following birth, and this process may potentially even occur in utero as mentioned previously. The initial composition of microbiota is derived from maternal colonic and vaginal flora that is acquired, in vaginally delivered infants, by passage through the birth canal. These microbiota include Enterobacteriae, Enterococci, and Staphylococci (33). Emerging evidence also suggests that placental transfer of microbes may also influence the development of the gut microbiome (34). The acquisition of gut microbiota appears to be an orderly process, with successive colonization of various bacterial classes beginning with Bacilli and then Gammaproteobacteria and Clostridia species (35). The intestinal microbiota is further developed and altered by feeding, particularly by breastfeeding, which contains prebiotics. These enterally delivered prebiotics promote the growth of commensal bacteria, which are beneficial to the infant (36). Term infants who are exclusively breastfed and born by vaginal delivery show a favorable composition of gut microbiota, with higher amounts of Bifidobacteria and lower amounts of Clostridium difficile and Escherichia coli compared to infants born by cesarean section and/or formula fed (37). Delivery in a hospital environment, compared to home, also leads to greater intestinal colonization by Clostridium difficile $(38,39)$.

In term infants, further expansion and alteration of the gut microbiota occurs with weaning from milk and the introduction of solid foods, with complete adult colonization by $2 \mathrm{y}$ of age (33). Additional factors such as exposure to family members and local environments also impact the development of the intestinal microbiome (40). However, once an infant reaches adulthood, the composition of gut commensal microbiota remains relatively stable (41). As we discuss further, a number of factors disrupt the acquisition of gut microbiota in preterm infants and these are likely to contribute to the development of NEC.

\section{INTERACTION OF MICROBIOTA WITH TOLL-LIKE RECEPTORS: MEDIATORS OF BOTH INTESTINAL HEALTH AND NEC}

The human intestine possesses "Pattern recognition receptors" (PRRs) that are able to specifically recognize "Microbial associated molecule patterns" or MAMPs. These PRRs then send signals that lead to cellular responses important in a number of homeostatic and host defense pathways. Common MAMPs include microbial cell-wall products such as lipopolysaccharide and peptidoglycan. Both commensal intestinal microbes and pathogens contain MAMPs, and normal flora can be proinflammatory under abnormal host conditions (42). Tolllike receptors (TLRs) are the most well-characterized PRR in the human intestine. These receptors must walk a tightrope between bacterial homeostatic vs. inflammatory effects in the preterm neonatal gut, as high-level activation by commensal microbiota can result in gut inflammation and injury. Activation of TLRs, while previously thought to be exclusively proinflammatory due to activation from pathogenic bacteria, is now known to also support important functions of intestinal health by activation from commensal bacteria (22). These functions include maintenance of intestinal homeostatsis by supporting cell growth and proliferation, cytoprotection, regulation of barrier function, and antimicrobial peptide secretion $(22,27,43)$. Mechanisms of gut tolerance to MAMPs are discussed in the next section.

Soon after birth, the preterm neonate receives a challenge of MAMPs through the acquisition of gut microbiota. Further, activation of TLR-4 occurs as part of the innate response to lipopolysaccharides from Gram-negative bacteria and has been implicated in the pathogenesis of NEC (44-46). In addition, the immature intestine, compared to a mature gut, is more likely to mount increased cytokine-mediated inflammatory responses by interleukin-8, which increases neutrophil chemotaxis and inflammation that can lead to tissue injury and NEC $(10,47)$. Some studies suggest that immature intestines may have a propensity for exaggerated inflammatory responses, due to deficient expression of inhibitors of the NF- $\kappa \mathrm{B}$ pathway, a major proinflammatory pathway $(7,8)$. In addition, the gut inflammatory response in preterm infants may be developmentally regulated (48), as mice demonstrate a peak in inflammatory response to colonization at a postnatal maturational 
window that is similar, in epithelial characteristics, to the gut of extremely preterm infants $(48,49)$. These findings have an obvious implication for NEC, as there is a developmental window that centers on a common postmenstrual age when most infants develop disease (50). Further, immature intestines may develop abnormal inflammatory responses as the gut becomes colonized due to downregulation of interleukin 1 receptorassociated kinase 1 in immature intestine, which is an essential component of TLR type 4 (TLR-4) signaling (51). This suggests that tolerance to MAMPs from gut microbes may require early exposure to microbial ligands to promote tolerance to the continued acquisition of commensal microbiota.

In addition to TLRs, other PRRs that mediate host-commensal and host-pathogen interaction include formyl-peptide receptors, G-protein coupled transmembrane receptors which are stimulated by microbial peptides $(52,53)$, and the NOD family of PRR, which detect intracytoplasmic MAMPs to mediate inflammation (54). Bacterial production of short chain fatty acids such as butyrate, which supports enterocytes growth and differentiation (55), can also decrease inflammation (56).

\section{TOLERANCE OF GUT MICROBIOTA}

The human gut must be able to house the beneficial microbiota that colonize it, without causing inflammation and injury. This is a remarkable feat, as the gut has numerous TLRs on its surface that are constantly sampling microbes and ready to mount an inflammatory response to protect the gut from pathogens. Commensal microbiota help the gut tolerate these microbes by preventing their recognition by the TLRs or by downregulating the proinflammatory NF- $\mathrm{KB}$ pathway (57). This is accomplished by blocking degradation of $\mathrm{I} \kappa \mathrm{B}$, an inhibitor of the proinflammatory NF- $\mathrm{KB}$ pathway (58). Probiotic bacteria, similar to commensal microbiota, can attenuate inflammation by regulating TLR- 4 dependent NF- $\kappa B$ activation through the same mechanism $(59,60)$. In addition, low-level activation of the TLR receptors by commensal microbiota play an important role in gut homeostasis, as previously mentioned.

\section{DISRUPTED ACQUISITION OF COMMENSAL MICROBIOTA}

Several factors may disrupt commensal colonization, by preventing or delaying the acquisition of commensal bacterial and lead to an abnormal composition of intestinal microbiota in premature infants (Figure 2). Prolonged antibiotic therapy can eliminate commensal bacteria and increase the risk of NEC, potentially by promoting colonization of more resistant pathogenic organisms which thrive in the hospital environment (61-64). Infants who receive antibiotic therapy soon after birth show lower amounts of Bifidobacteria (37). In addition, several studies have shown that prolonged empiric antibiotics therapy is associated with an increased risk of both NEC and lateonset sepsis $(61,63,64)$. As antibiotic therapy depletes the gut of commensal bacteria, innate and adaptive immune defense are also potentially altered and weakened (65). Similarly, the use of acid-suppression medications such as ranitidine are associated with an increased risk of NEC $(66,67)$, and a

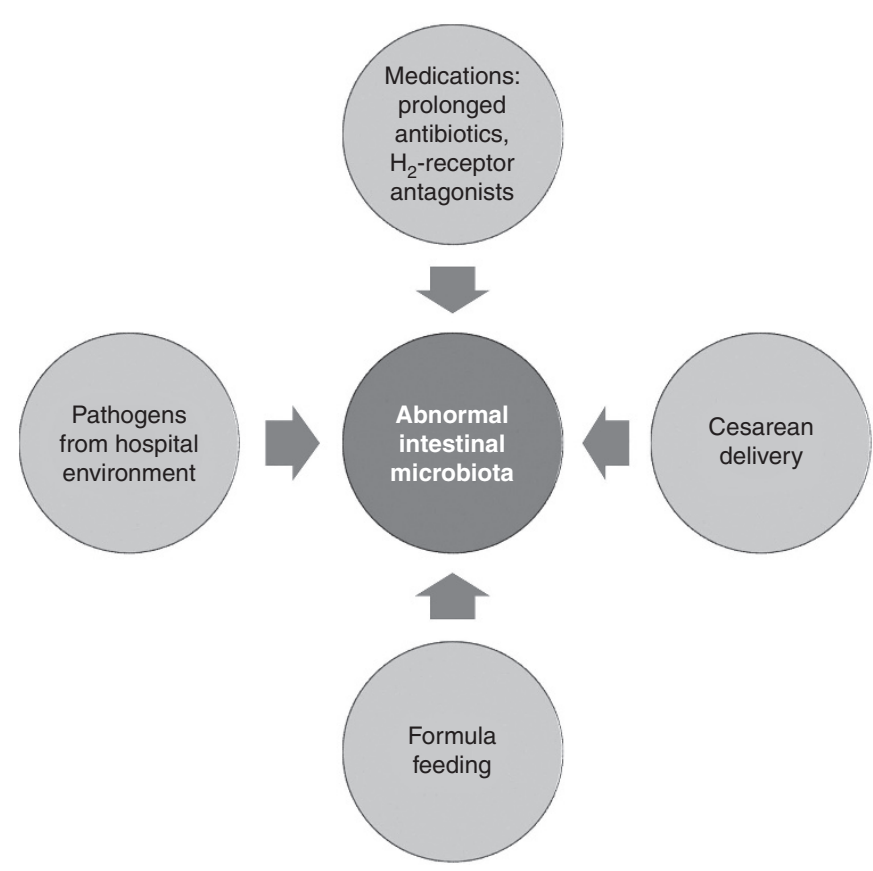

Figure 2. Factors disrupting the acquisition of commensal microbiota. Multiple factors promote abnormal gut colonization in preterm infants by delaying or disrupting the acquisition of beneficial commensal bacterial from the infant's mother and external environment.

lower fecal microbial diversity with a higher proportion of Enterobacteriaceae and fewer Firmicutes, which includes bacteria such as Lactobacillus (68).

Further, delivery by cesarean section instead of vaginal delivery, where the opportunity to acquire maternal flora from passage through the birth canal is lost, may lead to decreased colonization of beneficial commensal bacteria such as Bifidobacteria, Lactobacillus, and Bacteroides (37,69). In addition, the lack of human milk feeding, which contains important prebiotics that promote the growth of commensal bacteria, may further disrupt the acquisition and growth of commensal bacteria.

\section{DIFFERENCES IN THE INTESTINAL MICROBIOTA OF INFANTS WITH AND WITHOUT NEC}

Infants who develop NEC have altered gut microbiota compared to those infants without NEC. Culture-based studies, conducted over two decades ago, demonstrated differences in fecal bacteria up to $72 \mathrm{~h}$ before the onset of NEC (70). These changes in fecal bacteria included increases in Enterobacter cloacae and E. coli, with concomitant decreases in Streptococcus faecalis and Staphylococcal species.

More recent advances in nonculture-based methods have allowed for a molecular analysis of the gut microbiome of premature infants. These molecular-based studies have shown changes in the prevalence of Clostridum perfringens, Firmicutes, Proteobacteria, and Enterobacter prior to the onset of NEC (71-75). Further, decreases in Bifidobacteria and potential changes in yet unidentified strains similar to Klebsiella have also been described (76). These changes in the patterns of the developing gut microbiome occur rapidly after birth, within 


\section{Intestinal microbiota and NEC $\quad$ Review}

the first few weeks of postnatal age (77). Further, alterations in the microbiome in infants who later develop NEC occur as distant as $3 \mathrm{wk}$ prior to diagnosis (78). These studies suggests that the development of the early postnatal microbiome may be as important, if not more important, than the changes immediately prior to NEC onset. Further, infants with NEC tend to have a lower diversity of bacteria prior to the onset of NEC $(72,75)$. It is likely that known factors associated with NEC, such as formula feeding and extended empirical antibiotic use, may cause some of these changes observed in the gut microbiome of infants with NEC. This emerging literature has yet to show a consistent pattern with many different species purported to play a role in NEC pathogenesis. However, analysis of the intestinal microbial population is a complicated process which has yielded variable results from study to study. Results may differ due to platform used for data acquisition and/or sophistication of bioinformatics analysis. Further, variability in antibiotic therapy may be an important confounder in these studies.

\section{MICROBIAL PATHOGENS RECOVERED FROM INFANTS WITH NEC}

Although bloodstream infection develops in up to one-third of infants who develop NEC (79), it is unclear whether this is an effect of NEC, resulting from increased bacterial translocation from a disrupted intestinal barrier, or if bloodstream infection is involved in the pathogenesis of NEC. In these instances of co-occurrence of bacteremia with NEC, most bloodstream infections are caused by Gram-negative bacteria, predominantly by E. coli and Klebisella (80). Further, the presence of late-bacteremia with NEC may increase the risk of adverse neurodevelopmental outcome, particularly for infants who require surgical treatment for NEC (81).

\section{PROMOTING, PRESERVING, AND RESTORING HEALTHY GUT BACTERIA}

\section{Human milk feeding: promoting a beneficial gut microbiome}

Breastfeeding is associated with a lower risk of NEC. Part of the protective effect of breast milk is likely mediated by prebiotics within breast milk as well as the presence of beneficial Lactobacilli and Bifidobacteria (82). The presence of antiinflammatory cytokines such as interleukin-10 may also confer protection against NEC (83). Importantly, pasteurization of donor human milk may reduce these beneficial components in breast milk that influence the microbiota, although studies suggest that the use of donor human milk, when maternal breast milk is not available, may also lower the risk of NEC (84). Further, a single randomized trial demonstrates that the use of an exclusive human milk based diet with human milk derived fortifiers decreases the risk of surgical NEC (85), although additional confirmatory trials are necessary.

\section{Limiting prolonged empiric antibiotic therapy: preserving a beneficial gut microbiome}

Limiting the duration of prolonged empiric antibiotic therapy may help preserve a healthy quantity and balance of beneficial commensal bacteria. In a national network of academic centers in the United States, the duration of empiric antibiotic therapy for culture-negative early onset sepsis varied widely with the median duration of empiric treatment ranging from 3 to 9.5 $\mathrm{d}$ at any particular center (86). Further, data from this same study demonstrated that the odds of NEC was $40 \%$ higher for infants receiving 7 vs. $2 \mathrm{~d}$ of empiric antibiotic therapy for culture-negative sepsis. This association between early empiric antibiotic use and NEC has been validated in additional observational cohort studies $(63,64,75)$.

Given the relatively low incidence of culture-proven earlyonset sepsis, which is estimated to occur in $\sim 1 \%$ of infants with a birthweight of 401-1,500 $\mathrm{g}(87)$, reducing early antimicrobial exposure or duration of exposure may help reduce the risk of NEC. However, further studies are needed to determine better identification of neonates with a low probability of early-onset sepsis and develop tailored approaches to narrow the spectrum or duration of antibiotic exposure when treatment is necessary. Newer informatics approaches, including the use of clinical decision support (88), may be useful in reducing antibiotic exposure in the preterm population (89).

\section{Therapeutic modification of intestinal microbiota with probiotics and prebiotics}

Since abnormal gut microbiota is implicated in the pathogenesis of NEC, therapeutic modification of the gut microbiota is a logical approach to prevent NEC. Both prebiotics and probiotic bacteria can accomplish this goal. Therapeutic administration of probiotics can supply beneficial commensal strains that help protect the gut against intestinal inflammation and injury that may lead to NEC. Some of the mechanisms by which probiotics exert their beneficial effects include: (i) anti-inflammatory effects by attenuation of NF- $\mathrm{KB}$ activation (58); (ii) increases in cytoprotective gene responses $(23,90)$; (iii) promotion of barrier function by induction of tight junction protein expression $(9,91)$; (iv) generation of low levels of reactive oxygen species important in cell signaling $(48,92)$; (v) prevention of apoptosis and cell death $(90,93)$. Many different probiotic agents have been used to treat preterm infants (94), with clear efficacy in preventing NEC as demonstrated in a recent meta-analysis of 20 out of 24 randomized controlled trials enrolling $\sim 5,500$ neonates that demonstrate probiotics reduce both severe NEC (pooled relative risk (RR) 0.43; 95\% CI $0.33-0.56$ ) and all-cause mortality (RR 0.65; 95\% CI $0.52-$ 0.81 ) (95). The two most commonly used probiotic agents are from the genera Bifidobacteria and Lactobacillus. Both of these types of probiotics show similar efficacy in the prevention of NEC (96). Further, the aforementioned meta-analysis did not demonstrate any differences in effect by various subgroups of probiotic types, including Lactobacillus, Bifidobacterium, Sacchyromyces, or combinations thereof, $(P=0.48$ for test of subgroup differences).

Centers that have implemented the use of probiotic therapy as standard-of-care have demonstrated similar reductions in NEC, as reported in recent observational cohort studies from Canada (97) and Germany (98). These studies support 
the external validity of the results from the randomized trials. However, concerns regarding probiotic-associated sepsis and non-FDA regulated preparations have limited widespread use, although FDA-approved probiotic preparations are unlikely to be available in the near future (99). Importantly, a recent meta-analysis found no effect of probiotics on the risk of sepsis (pooled RR 0.92; 95\% CI 0.81-1.04), although there was significant heterogeneity among included studies (95). Of note, these studies have varied in species of probiotic used, dose (colony forming units per day), duration of therapy, selection criteria, and study population, all of which may influence the generalizability of the findings. Although insufficiently studied in the prevention of NEC, prebiotics such as GOS and/or FOS have been shown to increase beneficial commensal bacteria, such as Bifidobacteria, and may be another option in restoring a healthy balance of gut microbiota (100). However, a recent meta-analysis demonstrated prebiotic supplementation had no effect on NEC (101). In addition, prebiotic supplementation may have limited effects for infants already receiving mother's milk that contains prebiotics. This is highlighted by a recent study demonstrating a lack of significant increases in beneficial Bifidobacteria among prebiotic supplemented infants who were receiving maternal breast milk (102). In addition, prebiotics differ substantially between donor human milk and maternal breast milk, with some oligosaccharide concentrations higher and others lower in maternal breast milk compared to donor human milk (103).

\section{CONCLUSION}

In conclusion, intestinal microbiota can have both a protective and pathologic role in NEC. Achieving a healthy complement of commensal bacteria, potentially through interventions such as probiotic therapy, can promote and maintain a healthy composition of intestinal microbiota or shift the balance of intestinal microbiota from a pathogenic to protective complement. This in turn, may protect the preterm infant from gut inflammation and injury that can lead to the development of NEC.

\section{STATEMENT OF FINANCIAL SUPPORT}

This study was supported by the National Center for Advancing Translational Sciences of the National Institutes of Health (NIH, Bethesda, MD, USA) under Award Numbers KL2TR000455 and UL1TR000454 (R.M.P.) and R01 HD059122 (P.W.D). The content is solely the responsibility of the authors and does not necessarily represent the official views of the National Institutes of Health.

Disclosures: The authors do not have any relevant conflicts of interest.

\section{REFERENCES}

1. Lin PW, Stoll BJ. Necrotising enterocolitis. Lancet 2006;368:1271-83.

2. Neu J, Walker WA. Necrotizing enterocolitis. N Engl J Med 2011;364:255-64.

3. Fitzgibbons SC, Ching Y, Yu D, et al. Mortality of necrotizing enterocolitis expressed by birth weight categories. J Pediatr Surg 2009;44:1072-5; discussion 1075-6.

4. Hintz SR, Kendrick DE, Stoll BJ, et al.; NICHD Neonatal Research Network. Neurodevelopmental and growth outcomes of extremely low birth weight infants after necrotizing enterocolitis. Pediatrics 2005;115:696-703.

5. Stoll BJ, Kanto WP Jr, Glass RI, Nahmias AJ, Brann AW Jr. Epidemiology of necrotizing enterocolitis: a case control study. J Pediatr 1980;96(3 Pt 1): $447-51$.
6. Guthrie SO, Gordon PV, Thomas V, Thorp JA, Peabody J, Clark RH. Necrotizing enterocolitis among neonates in the United States. J Perinatol 2003;23:278-85.

7. Claud EC, Lu L, Anton PM, Savidge T, Walker WA, Cherayil BJ. Developmentally regulated IkappaB expression in intestinal epithelium and susceptibility to flagellin-induced inflammation. Proc Natl Acad Sci USA 2004;101:7404-8.

8. Nanthakumar NN, Fusunyan RD, Sanderson I, Walker WA. Inflammation in the developing human intestine: A possible pathophysiologic contribution to necrotizing enterocolitis. Proc Natl Acad Sci USA 2000;97:6043-8.

9. Patel RM, Myers LS, Kurundkar AR, Maheshwari A, Nusrat A, Lin PW. Probiotic bacteria induce maturation of intestinal claudin 3 expression and barrier function. Am J Pathol 2012;180:626-35.

10. Sharma R, Tepas JJ 3rd, Hudak ML, et al. Neonatal gut barrier and multiple organ failure: role of endotoxin and proinflammatory cytokines in sepsis and necrotizing enterocolitis. J Pediatr Surg 2007;42:454-61.

11. Lin PW, Nasr TR, Stoll BJ. Necrotizing enterocolitis: recent scientific advances in pathophysiology and prevention. Semin Perinatol 2008;32: $70-82$.

12. Singh R, Visintainer PF, Frantz ID 3rd, et al. Association of necrotizing enterocolitis with anemia and packed red blood cell transfusions in preterm infants. J Perinatol 2011;31:176-82.

13. Nowicki PT, Nankervis CA. The role of the circulation in the pathogenesis of necrotizing enterocolitis. Clin Perinatol 1994;21:219-34.

14. Mohamed A, Shah PS. Transfusion associated necrotizing enterocolitis: a meta-analysis of observational data. Pediatrics 2012;129:529-40.

15. Ip S, Chung M, Raman G, et al. Breastfeeding and maternal and infant health outcomes in developed countries. Evid Rep Technol Assess (Full Rep) 2007;153:1-186.

16. Lucas A, Cole TJ. Breast milk and neonatal necrotising enterocolitis. Lancet 1990;336:1519-23.

17. Anderson DM, Kliegman RM. The relationship of neonatal alimentation practices to the occurrence of endemic necrotizing enterocolitis. Am J Perinatol 1991;8:62-7.

18. Berseth CL, Bisquera JA, Paje VU. Prolonging small feeding volumes early in life decreases the incidence of necrotizing enterocolitis in very low birth weight infants. Pediatrics 2003;111:529-34.

19. Morgan J, Young L, McGuire W. Slow advancement of enteral feed volumes to prevent necrotising enterocolitis in very low birth weight infants. Cochrane Database Syst Rev 2013;3:CD001241.

20. Morgan J, Young L, McGuire W. Delayed introduction of progressive enteral feeds to prevent necrotising enterocolitis in very low birth weight infants. Cochrane Database Syst Rev 2013;5:CD001970.

21. Collier-Hyams LS, Neish AS. Innate immune relationship between commensal flora and the mammalian intestinal epithelium. Cell Mol Life Sci 2005;62:1339-48.

22. Rakoff-Nahoum S, Paglino J, Eslami-Varzaneh F, Edberg S, Medzhitov R. Recognition of commensal microflora by toll-like receptors is required for intestinal homeostasis. Cell 2004;118:229-41.

23. Hooper LV, Wong MH, Thelin A, Hansson L, Falk PG, Gordon JI. Molecular analysis of commensal host-microbial relationships in the intestine. Science 2001;291:881-4.

24. Bäckhed F, Ding H, Wang T, et al. The gut microbiota as an environmental factor that regulates fat storage. Proc Natl Acad Sci USA 2004;101: $15718-23$

25. Guarner F, Malagelada JR. Gut flora in health and disease. Lancet 2003;361:512-9.

26. Round JL, Mazmanian SK. The gut microbiota shapes intestinal immune responses during health and disease. Nat Rev Immunol 2009;9:313-23.

27. Abreu MT. Toll-like receptor signalling in the intestinal epithelium: how bacterial recognition shapes intestinal function. Nat Rev Immunol 2010;10:131-44.

28. Bäckhed F, Ley RE, Sonnenburg JL, Peterson DA, Gordon JI. Host-bacterial mutualism in the human intestine. Science 2005;307:1915-20.

29. Hooper LV, Gordon JI. Commensal host-bacterial relationships in the gut. Science 2001;292:1115-8. 
30. Ardissone AN, de la Cruz DM, Davis-Richardson AG, et al. Meconium microbiome analysis identifies bacteria correlated with premature birth. PLoS One 2014;9:e90784.

31. Lohmann P, Luna RA, Hollister EB, et al. The airway microbiome of intubated premature infants: characteristics and changes that predict the development of bronchopulmonary dysplasia. Pediatr Res 2014;76:294-301.

32. Pennisi E. Microbiology. Contamination plagues some microbiome studies. Science 2014;346:801.

33. Claud EC, Walker AW. The Intestinal Microbiota and the Microbiome. New York: Saunders, 2008.

34. Aagaard K, Ma J, Antony KM, Ganu R, Petrosino J, Versalovic J. The placenta harbors a unique microbiome. Sci Translational Med 2014;6:237ra65.

35. La Rosa PS, Warner BB, Zhou Y, et al. Patterned progression of bacterial populations in the premature infant gut. Proc Natl Acad Sci USA 2014;111:12522-7.

36. Ouwehand AC, Derrien M, de Vos W, Tiihonen K, Rautonen N. Prebiotics and other microbial substrates for gut functionality. Curr Opin Biotechnol 2005;16:212-7.

37. Penders J, Thijs C, Vink C, et al. Factors influencing the composition of the intestinal microbiota in early infancy. Pediatrics 2006;118:511-21.

38. Bacon AE, Fekety R, Schaberg DR, Faix RG. Epidemiology of Clostridium difficile colonization in newborns: results using a bacteriophage and bacteriocin typing system. J Infect Dis 1988;158:349-54.

39. Delmée M, Verellen G, Avesani V, Francois G. Clostridium difficile in neonates: serogrouping and epidemiology. Eur J Pediatr 1988;147:36-40.

40. Madan JC, Farzan SF, Hibberd PL, Karagas MR. Normal neonatal microbiome variation in relation to environmental factors, infection and allergy. Curr Opin Pediatr 2012;24:753-9.

41. Faith JJ, Guruge JL, Charbonneau M, et al. The long-term stability of the human gut microbiota. Science 2013;341:1237439.

42. Cario E, Brown D, McKee M, Lynch-Devaney K, Gerken G, Podolsky DK. Commensal-associated molecular patterns induce selective toll-like receptor-trafficking from apical membrane to cytoplasmic compartments in polarized intestinal epithelium. Am J Pathol 2002;160:165-73.

43. Cario E, Gerken G, Podolsky DK. Toll-like receptor 2 controls mucosal inflammation by regulating epithelial barrier function. Gastroenterology 2007;132:1359-74.

44. Sodhi CP, Neal MD, Siggers R, et al. Intestinal epithelial Toll-like receptor 4 regulates goblet cell development and is required for necrotizing enterocolitis in mice. Gastroenterology 2012;143:708-18.e1-5.

45. Lu P, Sodhi CP, Hackam DJ. Toll-like receptor regulation of intestinal development and inflammation in the pathogenesis of necrotizing enterocolitis. Pathophysiology 2014;21:81-93.

46. Yazji I, Sodhi CP, Lee EK, et al. Endothelial TLR4 activation impairs intestinal microcirculatory perfusion in necrotizing enterocolitis via eNOS-NOnitrite signaling. Proc Natl Acad Sci USA 2013;110:9451-6.

47. Markel TA, Crisostomo PR, Wairiuko GM, Pitcher J, Tsai BM, Meldrum DR. Cytokines in necrotizing enterocolitis. Shock 2006;25:329-37.

48. Lin PW, Myers LE, Ray L, et al. Lactobacillus rhamnosus blocks inflammatory signaling in vivo via reactive oxygen species generation. Free Radic Biol Med 2009;47:1205-11.

49. McCracken VJ, Lorenz RG. The gastrointestinal ecosystem: a precarious alliance among epithelium, immunity and microbiota. Cell Microbiol 2001;3:1-11.

50. Gordon PV, Clark R, Swanson JR, Spitzer A. Can a national dataset generate a nomogram for necrotizing enterocolitis onset? J Perinatol 2014;34:732-5.

51. Lotz M, Gütle D, Walther S, Ménard S, Bogdan C, Hornef MW. Postnatal acquisition of endotoxin tolerance in intestinal epithelial cells. J Exp Med 2006;203:973-84.

52. Wentworth CC, Alam A, Jones RM, Nusrat A, Neish AS. Enteric commensal bacteria induce extracellular signal-regulated kinase pathway signaling via formyl peptide receptor-dependent redox modulation of dual specific phosphatase 3. J Biol Chem 2011;286:38448-55.

53. Wentworth CC, Jones RM, Kwon YM, Nusrat A, Neish AS. Commensalepithelial signaling mediated via formyl peptide receptors. Am J Pathol 2010;177:2782-90.

\section{Intestinal microbiota and NEC ReVIOW}

54. Girardin SE, Tournebize R, Mavris $M$, et al. CARD4/Nod1 mediates NF-kappaB and JNK activation by invasive Shigella flexneri. EMBO Rep 2001;2:736-42.

55. Bartholome AL, Albin DM, Baker DH, Holst JJ, Tappenden KA. Supplementation of total parenteral nutrition with butyrate acutely increases structural aspects of intestinal adaptation after an $80 \%$ jejunoileal resection in neonatal piglets. JPEN J Parenter Enteral Nutr 2004;28:210-22; discussion 222-3.

56. Yin L, Laevsky G, Giardina C. Butyrate suppression of colonocyte NF-kappa B activation and cellular proteasome activity. J Biol Chem 2001;276:44641-6.

57. Neish AS. Molecular aspects of intestinal epithelial cell-bacterial interactions that determine the development of intestinal inflammation. Inflamm Bowel Dis 2004;10:159-68.

58. Neish AS, Gewirtz AT, Zeng H, et al. Prokaryotic regulation of epithelial responses by inhibition of IkappaB-alpha ubiquitination. Science 2000;289:1560-3.

59. Iyer C, Kosters A, Sethi G, Kunnumakkara AB, Aggarwal BB, Versalovic J. Probiotic Lactobacillus reuteri promotes TNF-induced apoptosis in human myeloid leukemia-derived cells by modulation of NF-kappaB and MAPK signalling. Cell Microbiol 2008;10:1442-52.

60. Tien MT, Girardin SE, Regnault B, et al. Anti-inflammatory effect of Lactobacillus casei on Shigella-infected human intestinal epithelial cells. J Immunol 2006;176:1228-37.

61. Cotten CM, Taylor S, Stoll B, et al.; NICHD Neonatal Research Network. Prolonged duration of initial empirical antibiotic treatment is associated with increased rates of necrotizing enterocolitis and death for extremely low birth weight infants. Pediatrics 2009;123:58-66.

62. Kenyon S, Boulvain M, Neilson J. Antibiotics for preterm premature rupture of membranes. Cochrane Database Syst Rev 2001;4:CD001058.

63. Kuppala VS, Meinzen-Derr J, Morrow AL, Schibler KR. Prolonged initial empirical antibiotic treatment is associated with adverse outcomes in premature infants. J Pediatr 2011;159:720-5.

64. Alexander VN, Northrup V, Bizzarro MJ. Antibiotic exposure in the newborn intensive care unit and the risk of necrotizing enterocolitis. J Pediatr 2011;159:392-7.

65. Ubeda C, Pamer EG. Antibiotics, microbiota, and immune defense. Trends Immunol 2012;33:459-66.

66. Guillet R, Stoll BJ, Cotten CM, et al.; National Institute of Child Health and Human Development Neonatal Research Network. Association of H2-blocker therapy and higher incidence of necrotizing enterocolitis in very low birth weight infants. Pediatrics 2006;117:e137-42.

67. Terrin G, Passariello A, De Curtis M, et al. Ranitidine is associated with infections, necrotizing enterocolitis, and fatal outcome in newborns. Pediatrics 2012;129:e40-5.

68. Gupta RW, Tran L, Norori J, et al. Histamine-2 receptor blockers alter the fecal microbiota in premature infants. J Pediatr Gastroenterol Nutr 2013;56:397-400.

69. Westerbeek EA, van den Berg A, Lafeber HN, Knol J, Fetter WP, van Elburg RM. The intestinal bacterial colonisation in preterm infants: a review of the literature. Clin Nutr 2006;25:361-8.

70. Hoy C, Millar MR, MacKay P, Godwin PG, Langdale V, Levene MI. Quantitative changes in faecal microflora preceding necrotising enterocolitis in premature neonates. Arch Dis Child 1990;65(10 Spec No):1057-9.

71. de la Cochetiere MF, Piloquet H, des Robert C, Darmaun D, Galmiche JP, Roze JC. Early intestinal bacterial colonization and necrotizing enterocolitis in premature infants: the putative role of Clostridium. Pediatr Res 2004;56:366-70.

72. Wang Y, Hoenig JD, Malin KJ, et al. 16S rRNA gene-based analysis of fecal microbiota from preterm infants with and without necrotizing enterocolitis. ISME J 2009;3:944-54.

73. Morrow AL, Lagomarcino AJ, Schibler KR, et al. Early microbial and metabolomic signatures predict later onset of necrotizing enterocolitis in preterm infants. Microbiome 2013;1:13.

74. Mai V, Young CM, Ukhanova $\mathrm{M}$, et al. Fecal microbiota in premature infants prior to necrotizing enterocolitis. PLoS One 2011;6:e20647. 
75. Greenwood C, Morrow AL, Lagomarcino AJ, et al. Early empiric antibiotic use in preterm infants is associated with lower bacterial diversity and higher relative abundance of Enterobacter. J Pediatr 2014;165:23-9.

76. Torrazza RM, Ukhanova M, Wang X, et al. Intestinal microbial ecology and environmental factors affecting necrotizing enterocolitis. PLoS One 2013;8:e83304.

77. Moles L, Gómez M, Heilig H, et al. Bacterial diversity in meconium of preterm neonates and evolution of their fecal microbiota during the first month of life. PLoS One 2013;8:e66986.

78. Claud EC, Keegan KP, Brulc JM, et al. Bacterial community structure and functional contributions to emergence of health or necrotizing enterocolitis in preterm infants. Microbiome 2013;1:20.

79. Lee JS, Polin RA. Treatment and prevention of necrotizing enterocolitis. Semin Neonatol 2003;8:449-59.

80. Bizzarro MJ, Ehrenkranz RA, Gallagher PG. Concurrent bloodstream infections in infants with necrotizing enterocolitis. J Pediatr 2014;164: 61-6.

81. Martin CR, Dammann O, Allred EN, et al. Neurodevelopment of extremely preterm infants who had necrotizing enterocolitis with or without late bacteremia. J Pediatr 2010;157:751-6.e1.

82. Soto A, Martin V, Jimenez E, Mader I, Rodriguez JM, Fernandez L. Lactobacilli and Bifidobacteria in human breast milk: influence of antibiotherapy and other host and clinical factors. J Pediatr Gastroenterol Nutr 2014;59(1):78-88.

83. Dvorak B, Halpern MD, Holubec $\mathrm{H}$, et al. Maternal milk reduces severity of necrotizing enterocolitis and increases intestinal IL-10 in a neonatal rat model. Pediatr Res 2003;53:426-33.

84. Quigley M, McGuire W. Formula versus donor breast milk for feeding preterm or low birth weight infants. Cochrane Database Syst Rev 2014;4:CD002971.

85. Cristofalo EA, Schanler RJ, Blanco CL, et al. Randomized trial of exclusive human milk versus preterm formula diets in extremely premature infants. J Pediatr 2013;163:1592-1595.e1.

86. Cotten CM, Taylor S, Stoll B, et al.; NICHD Neonatal Research Network. Prolonged duration of initial empirical antibiotic treatment is associated with increased rates of necrotizing enterocolitis and death for extremely low birth weight infants. Pediatrics 2009;123:58-66.

87. Stoll BJ, Hansen NI, Sánchez PJ, et al.; Eunice Kennedy Shriver National Institute of Child Health and Human Development Neonatal Research Network. Early onset neonatal sepsis: the burden of group B Streptococcal and E. coli disease continues. Pediatrics 2011;127:817-26.

88. Samore $\mathrm{MH}$, Bateman K, Alder SC, et al. Clinical decision support and appropriateness of antimicrobial prescribing: a randomized trial. JAMA 2005;294:2305-14.
89. Coggins SA, Wynn JL, Hill ML, et al. Use of a computerized C-reactive protein (CRP) based sepsis evaluation in very low birth weight (VLBW) infants: a five-year experience. PLoS One 2013;8:e78602.

90. Lin PW, Nasr TR, Berardinelli AJ, Kumar A, Neish AS. The probiotic Lactobacillus GG may augment intestinal host defense by regulating apoptosis and promoting cytoprotective responses in the developing murine gut. Pediatr Res 2008;64:511-6.

91. Khailova L, Dvorak K, Arganbright KM, et al. Bifidobacterium bifidum improves intestinal integrity in a rat model of necrotizing enterocolitis. Am J Physiol Gastrointest Liver Physiol 2009;297:G940-9.

92. Kumar A, Wu H, Collier-Hyams LS, et al. Commensal bacteria modulate cullin-dependent signaling via generation of reactive oxygen species. EMBO J 2007;26:4457-66.

93. Khailova L, Mount Patrick SK, Arganbright KM, Halpern MD, Kinouchi T, Dvorak B. Bifidobacterium bifidum reduces apoptosis in the intestinal epithelium in necrotizing enterocolitis. Am J Physiol Gastrointest Liver Physiol 2010;299:G1118-27.

94. Patel RM, Denning PW. Therapeutic use of prebiotics, probiotics, and postbiotics to prevent necrotizing enterocolitis: what is the current evidence? Clin Perinatol 2013;40:11-25.

95. AlFaleh K, Anabrees J. Probiotics for prevention of necrotizing enterocolitis in preterm infants. Cochrane Database Syst Rev 2014;4:CD005496.

96. Wang Q, Dong J, Zhu Y. Probiotic supplement reduces risk of necrotizing enterocolitis and mortality in preterm very low-birth-weight infants: an updated meta-analysis of 20 randomized, controlled trials. J Pediatr Surg 2012;47:241-8.

97. Janvier A, Malo J, Barrington KJ. Cohort study of probiotics in a North American neonatal intensive care unit. J Pediatr 2014;164:980-5.

98. Härtel C, Pagel J, Rupp J, et al.; German Neonatal Network. Prophylactic use of Lactobacillus acidophilus/Bifidobacterium infantis probiotics and outcome in very low birth weight infants. J Pediatr 2014;165:285-289.e1.

99. Shane AL, Deshpande GC, Merenstein D. Improved neonatal outcomes with probiotics. JAMA Pediatr 2013;167:885-6.

100. Srinivasjois R, Rao S, Patole S. Prebiotic supplementation of formula in preterm neonates: a systematic review and meta-analysis of randomised controlled trials. Clin Nutr 2009;28:237-42.

101. Srinivasjois R, Rao S, Patole S. Prebiotic supplementation in preterm neonates: updated systematic review and meta-analysis of randomised controlled trials. Clin Nutr 2013;32:958-65.

102. Underwood MA, Kalanetra KM, Bokulich NA, et al. Prebiotic oligosaccharides in premature infants. J Pediatr Gastroenterol Nutr 2014;58:352-60.

103. Marx C, Bridge R, Wolf AK, Rich W, Kim JH, Bode L. Human milk oligosaccharide composition differs between donor milk and mother's own milk in the NICU. J Hum Lact 2014;30:54-61. 